\title{
Prevalence of invasive Trichosporonosis by Trichosporon asahii and other Trichosporon species and their antifungal susceptibility pattern in Chhattisgarh
}

\author{
Pradhan $\mathrm{S}^{1}$, Agrawal $\mathrm{E}^{2}$, Murthy $\mathbf{R}^{3}$, Tomar $\mathrm{R}^{4}$ \\ ${ }^{1}$ Dr. Sagarika Pradhan, ${ }^{2}$ Dr. Ekta Agrawal, ${ }^{3}$ Dr. Ramanesh Murthy, Professor and Head, ${ }^{4}$ Dr. Rashmi Tomar, Assistant \\ Professor; all authors are attached with Department of Microbiology, Chhattisgarh Institute of Medical Sciences, \\ Bilaspur, Chhattisgarh, India
}

Address for Correspondence: Dr. Sagarika Pradhan, E-mail: microbiology.cims@gmail.com

\begin{abstract}
Introduction: Trichosporonosis is usually known to cause superficial mycoses, but now it is emerged as an opportunistic infectious disease. Trichosporon species is fairly uncommon fungus but can cause fatal mycosis in immunocompromised patients. Objective: This study is an attempt to know prevalence of invasive trichosporonosis and its antifungal susceptibility. Materials and Methods: All patients with a culture that was positive for Trichosporon species from February 2012 to February 2015 were included. Routine mycology works up done and suspected Trichosporon sp. were confirmed by automated miniAPI system. Antifungal susceptibility test was done for Fluconazole (F), Itraconazole (Itr), Voriconazole(V), Flucytosine (5Fc), AmphotericinB (AMB) done by minimum inhibitory concentration (MIC) method by ATB Fungus3 ( Biomerieux, France). Result: 41 Trichosporon sp. was isolated from clinical specimen. Trichosporon asahii was the most common isolate ( 29 out of $41,70.7 \%$ ), followed by T. mucoides ( 5 of $41,12.2 \%$ ), T. inkin ( 2 of 41 , $4.9 \%$ ) and other Trichosporon sp. (5 out of $41,12.2 \%$ ). Out of 41,20 cases were proven to cause invasive trichosporonosis. Most invasive infections were associated with indwelling catheter (95\%), associated bacterial infection $(85 \%)$, ICU stay $(85 \%$ each), prior antibiotic use $(75 \%)$, cancer $(65 \%)$, neutropenia, steroid use (55\% each) and chemotherapy (50\%). Amphotericin B was less susceptible against Trichosporon isolates whereas azole had good in vitro activity. Sensitivity of T.asahii towards Fluconazole, Itraconazole, Voriconazole, Amphotericin B and Flucytosine was 72.4\%, 51.7\%, 86.2\%, 51.7\% and 66.8\% respectively. Conclusion: T. asahii and other unusual Trichosporon sp.species also cause invasive trichosporonosis. For optimal therapy for trichosporonosis azoles can play a potential role.
\end{abstract}

Keywords: Trichosporonosis, Trichosporon species, T.asahii, Antifungal susceptibility.

\section{Introduction}

Fungi are known to mankind since a long time and omnipresent in environment. However, reports emanating from mycological works are very few and far in between. Therefore, their clinical relevance often gets neglected. But with changing health scenario, fungi are now considered as an emerging pathogen [1]. The annual incidence of mycoses was increased by over $200 \%$ in between 1979 to 2000 [2]. Though nonalbicans Candida are the most common fungal pathogens encountered in clinical specimens [2, 3], now-a-days infection due to Trichosporon $s p$. are

Manuscript received: $8^{\text {th }}$ March 2017

Reviewed: $17^{\text {th }}$ March 2017

Author Corrected: $24^{\text {th }}$ March 2017

Accepted for Publication: $31^{\text {st }}$ March 2017 increasing. It is one of the least understood among emerging opportunistic pathogens causing fatal fungal infection in immunocompromised patients [4]. It is associated with spectrum of clinical diseases from superficial cutaneous mycoses in immunocompetent individual to severe invasive systemic diseases in immunocompromised patients [5].

Trichosporon Behrend is a basidiomycetes yeast, with a unique morphological characters of budding cell and true mycelium that disarticulate to form arthroconidia $[6,7]$. Previously, only one species $T$. beigelli was reported as pathological etiological agent for superficial infection such as white piedra, nail infection \& tinea 
cruris [8]. Now on the basis of ultrastructure \& DNA studies, T. beigelli has been divided into number of species. Among them major human pathogens are $-T$. asahii, T. astoreoides, T. mucoides, T. cutanei, T. ovoides, T. inkin, T. loubieri [9].

It is present in environment, mainly in soil, water, air and organic substance. It is also present as normal flora of human skin \& gastrointestinal tract [9-11]. Among different Trichosporon sp. T. asahii is the most important pathogen in imunocompromised and granulocytopenic patients $[4,12]$.

In routine laboratory set up, usually its diagnosis is likely to be missed, particularly in developing countries. It is due to lack of awareness and lack of acquaintance with the salient diagnostic feature of the etiologic agent.

Barring a few isolated case-reports, there is no information on the prevalence of disseminated invasive Trichosporonosis in India.Most of the time Trichosporon sp. are reported as nonalbicans Candida in routine laboratory study. The aim of this study is to investigate the prevalence of Trichosporon sp. in population of Chhattisgarh along with spectrum of clinical features and antifungal susceptibility.

\section{Materials and Methods}

This retrospective study was conducted in Department of Microbiology of Chhattisgarh Institute of Medical Sciences, Bilaspur, Chhattisgarh from February 2012 to February 2015. After taking the permission from ethical committee, all patients with a culture positive for Trichosporon $s p$. from clinical specimen included in this study except skin and hair.

Whenever required, a second specimen was requested for confirmation. The strain Candida albicans American type culture collection (ATCC) 14053 was used as control.

Methods: The blood culture was done by automated BacT/ALERT (Biomerieux, France) blood culture system. On getting growth signal, gram stain of blood culture broth showed elongated blastoconidia and septate pseudohyphae.

Broth from the positive blood cultures bottles were subcultured on blood agar (Hi Media, India) and Sabouraud's Dextrose agar with Chloramphenicol
(SDA) (Hi Media, India) and incubated at $37^{\circ} \mathrm{C}$. After 24 to 48 hours of incubation, the colonies of yeast like fungi were isolated.

Pus, body fluids, sputum, cerebrospinal fluid (CSF) etc. were inoculated on Blood agar, MacConkey Agar (Hi Media, India) and SDA. Urine specimens were inoculated on Cystein Lactose Electrolyte Deficient (Hi Media, India) and SDA. Culture plates were incubated aerobically at $37^{\circ} \mathrm{C}$ for $24-48$ hours. Gram stain showed gram positive blastoconidia and pseudohyphae. To differentiate from Candida sp., germ tube test, urease test and corn meal test were done.

Fungus with negative germ tube test, positive urease test and arthroconidia in Corn Meal test were suspected as Trichosporon sp. All suspected Trichosporon isolates were identified up to the species level by standard laboratory procedures, including morphological identification \& ID 32C strips of miniAPI (Biomerieux, France).

Antifungal susceptibility test for Fluconazole (F), Itraconazole (Itr), Voriconazole (V), Flucytosine $(5 \mathrm{Fc})$ and AmphotericinB (AMB) was done by minimum inhibitory concentration (MIC) method by ATB Fungus 3 (Biomerieux, France). The macroscopic and microscopic morphology of Trichosporon sp. was compatible with the standard description of the species.

Invasive fungal infection was defined according to Invasive Fungal Infection Co-operation Group of European Organisation for Research \& Treatment of Cancer and mycoses study group of National Institute of Allergy \& Infectious Diseases [13]. According to this group invasive Trichosporonosis was defined as "proven" or "probable" cases.Invasive Trichosporonosis was considered as "proven", when one or more of the following criteria were met: (1) blood culture yielding Trichosporon sp. in patients with clinical sign and symptoms (2) positive CSF culture for Trichosporon sp. (3) positive tissue biopsy culture for Trichosporon sp. with histopathological evidence of fungal growth.

Cases with following criteria were defined as "probable": (1) presence of at least one host factor criterion: neutropenia, cancer, on immunosuppressive therapy, fever refractory to broad spectrum antibiotics (2) one microbiological criterion (3) one major clinical criterion consistent with infection i.e. imaging. 


\section{Results}

During 3 years study period, 41 isolates of Trichosporon $s p$. were cultured from various clinical specimens from the patients. Out of 41 isolates, 25 isolates were from male patients (61\%) and $16(39 \%)$ from female patients, indicating male preponderance (table 1). Maximum 15 isolates (36.6\%) were from patients of 61-80 years age group, followed by 11 isolates $(26.8 \%)$ in $41-60$ years age group, 9 isolates $(21.9 \%)$ were from patients of 0-20 years age group. From the above distribution, Trichosporonosis appears to be more frequent at extreme of age group. Out of 9 patients of 0-20 years age group, 8 patients were below one year age. Out of 41, 20 patients (48.8\%) had proven invasive Trichosporonosis whereas 21 patients $(51.2 \%)$ had probable invasive Trichosporonosis.

Table No-1: Age distribution of patients included in the study $(n=41)$.

\begin{tabular}{|c|c|c|c|c|c|c|}
\hline Age & Male & Female & Total & $\begin{array}{c}\text { Proven invasive } \\
\text { Trichosporonosis }\end{array}$ & $\begin{array}{c}\text { Probable invasive } \\
\text { Trichosporonosis }\end{array}$ & $\begin{array}{c}\text { P } \\
\text { value* }\end{array}$ \\
\hline 0-20 years & $6(14.6 \%)$ & $3(7.3 \%)$ & $9(21.9 \%)$ & 8 & 1 & $<0.05$ \\
\hline $21-40$ years & $4(9.7 \%)$ & $2(4.9 \%)$ & $6(14.6 \%)$ & 3 & 7 \\
\hline $41-60$ years & $6(14.6 \%)$ & $5(12.2 \%)$ & $11(26.8 \%)$ & 4 & 10 \\
\hline $61-80$ years & $9(22 \%)$ & $6(14.6 \%)$ & $15(36.6 \%)$ & 5 & $\mathbf{2 1}$ \\
\hline Total & $\mathbf{2 5 ( 6 1 \% )}$ & $\mathbf{1 6}(\mathbf{3 9 \%})$ & $\mathbf{4 1 ( 1 0 0 \% )}$ & $\mathbf{2 0}$ & \\
\hline
\end{tabular}

* P Value calculated by chi square rule.

From the above table 1 , we calculated $\mathrm{p}$ value which was $<0.05$, which showed association between age interval and proven invasive Trichosporonosis.

Table No-2: Specimen wise distribution of Trichosporon species $(n=41)$.

\begin{tabular}{|c|c|c|c|c|c|c|}
\hline Specimen & T. asahii & T. mucoides & T.inkin & $\begin{array}{c}\text { Other } \\
\text { Trichosporon }\end{array}$ & Total & $\begin{array}{c}\text { Proven invasive } \\
\text { Trichosporonosis }\end{array}$ \\
\hline Blood & 10 & 1 & 1 & 1 & $13(31.7 \%)$ & $13(65 \%)$ \\
\hline CSF & 3 & 0 & 0 & 0 & $3(7.3 \%)$ & $3(15 \%)$ \\
\hline Urine & 6 & 2 & 1 & 1 & $10(24.4 \%)$ & $0(0 \%)$ \\
\hline Pus & 3 & 1 & 0 & 1 & $5(12.2 \%)$ & $1(5 \%)$ \\
\hline $\begin{array}{c}\text { ET } \\
\text { Aspirates }\end{array}$ & 4 & 1 & 0 & 1 & $6(14.6 \%)$ & $2(10 \%)$ \\
\hline $\begin{array}{c}\text { Other } \\
\text { specimen }\end{array}$ & 3 & 0 & 0 & 1 & $4(9.7 \%)$ & 0 \\
\hline Total & $\mathbf{2 9}(\mathbf{7 0 . 7 \% )}$ & $\mathbf{5 ( 1 2 . 2 \% )}$ & $\mathbf{2 ( 4 . 9 \% )}$ & $\mathbf{5 ( 1 2 . 2 \% )}$ & $\mathbf{4 1 ( 1 0 0 \% )}$ & $\mathbf{2 0}(\mathbf{1 0 0 \% )}$ \\
\hline
\end{tabular}

In our study, Trichosporon sp. was isolated from wide range of clinical specimen. As shown in the table 2, T.asahii was isolated from 29 specimen (70.7\%), T.mucoides from 5(12.2\%), T. inkin from only 2 specimen (4.9\%), other Trichosporon sp. 5 (12.2\%). In our study T.asahii was the most common species of Trichospron isolated. Out of 20 proven invasive Trichosporonosis, 13 had blood stream infection, three had central nervous system infection, two had pneumonia and only one had soft tissue infection.

As shown in table 3, out of 20 invasive Trichosporonosis, $40 \%$ patients were below 1 year of age whereas $25 \%$ patients were above 60 years of age. The most common associated risk factor for proven Trichosporonosis was indwelling catheter (95\%), associated bacterial infection (85\%), ICU stay (85\%), prior antibiotic use (75\%), cancer $(65 \%)$, neutropenia $(55 \%)$, steroid use $(55 \%)$ and chemotherapy(50\%). Other risk factors include dialysis and diabetes mellitus and road traffic accidents. 
Table No-3: Risk factors associated with Trichosporonosis $(n=41)$.

\begin{tabular}{|c|c|c|c|}
\hline Risk factors & $\begin{array}{l}\text { Number of patients } \\
\qquad(n=41)\end{array}$ & $\begin{array}{l}\text { Proven invasive } \\
\text { Trichosporonosis } \\
(\mathbf{n}=\mathbf{2 0})\end{array}$ & $\begin{array}{c}\text { Probable } \\
\text { Trichosporonosis } \\
(\mathbf{n}=21)\end{array}$ \\
\hline Age $<1$ year & $8(19.5 \%)$ & $8(40 \%)$ & $1(4.8 \%)$ \\
\hline Age $>60$ year & $15(36.6 \%)$ & $5(25 \%)$ & $10(47.6 \%)$ \\
\hline Cancer & $17(41.5 \%)$ & $13(65 \%)$ & $4(19 \%)$ \\
\hline On chemotherapy & $11(26.8 \%)$ & $10(50 \%)$ & $1(4.8 \%)$ \\
\hline Prior antibiotic use & $35(85.4 \%)$ & $15(75 \%)$ & $20(95.2 \%)$ \\
\hline Intravenous catheter & $32(78 \%)$ & $19(95 \%)$ & $13(61.9 \%)$ \\
\hline ICU stay & $36(87.8 \%)$ & $17(85 \%)$ & $19(90.4 \%)$ \\
\hline Steroid use & $28(68.3 \%)$ & $11(55 \%)$ & $17(80.9 \%)$ \\
\hline Neutropenia $<500$ cell $/ \mathrm{mm} 3$ & $15(36.6 \%)$ & $11(55 \%)$ & $4(19 \%)$ \\
\hline Dialysis & $7(17.1 \%)$ & $2(10 \%)$ & $4(19 \%)$ \\
\hline Diabetes & $13(31.7 \%)$ & $5(25 \%)$ & $8(38 \%)$ \\
\hline Road traffic accident & $7(17.1 \%)$ & $3(15 \%)$ & $4(19 \%)$ \\
\hline Associated bacterial infection & $28(68.3 \%)$ & $17((85 \%)$ & $11(52.4 \%)$ \\
\hline
\end{tabular}

Antifungal susceptibility pattern: As no MIC interpretative criteria for Trichosporon sp. was available, the interpretative criteria for Candida species were used as reference purpose [14, 15]. They were considered as sensitive, resistant and intermediate (susceptible dose depended in case of Fluconazole) by miniAPI as per M27A3 of Clinical and Laboratory Standards Institute (CLSI) guideline [16]. Only 21 out of 29 (72.4\%) T.asahii were sensitive to Fluconazole (F) and 25 out of $29(86.2 \%)$ were sensitive to Voriconazole (V) whereas other Trichosporon sp. was $58.3 \%$ sensitive to

Table No-4: Antifungal susceptibility of Trichosporon isolates (n=41).

\begin{tabular}{|c|c|c|c|c|c|}
\hline $\begin{array}{l}\text { Antifungal } \\
\text { agents }\end{array}$ & T.asahii $(\mathrm{n}=29)$ & $\begin{array}{l}\text { T.mucoides } \\
\quad(n=5)\end{array}$ & T.inkin $(\mathrm{n}=2)$ & $\begin{array}{c}\text { Other } \\
\text { Trichosporon }(\mathrm{n}=5)\end{array}$ & $\begin{array}{c}\text { Trichosporon } \\
\text { other than } \\
\text { T.asahii }(\mathrm{n}=12)\end{array}$ \\
\hline $\begin{array}{l}\text { Fluconazole } \\
\text { Sensitive } \\
\text { Resistant } \\
\text { Intermediate }\end{array}$ & $\begin{array}{l}21(72.4 \%) \\
3(10.3 \%) \\
5(17.3 \%)\end{array}$ & $\begin{array}{l}2(40 \%) \\
2(40 \%) \\
1(20 \%)\end{array}$ & $\begin{array}{c}2(100 \%) \\
0 \\
0\end{array}$ & $\begin{array}{l}3(60 \%) \\
1(20 \%) \\
1(20 \%)\end{array}$ & $\begin{array}{c}7(58.3 \%) \\
3(25 \%) \\
2(16.7 \%)\end{array}$ \\
\hline $\begin{array}{l}\text { Itraconazole } \\
\text { Sensitive } \\
\text { Resistant } \\
\text { Intermediate }\end{array}$ & $\begin{array}{c}15(51.7 \%) \\
12(41.4 \%) \\
2(6.9 \%)\end{array}$ & $\begin{array}{l}3(60 \%) \\
1(20 \%) \\
1(20 \%)\end{array}$ & $\begin{array}{c}1(50 \%) \\
1(50 \%) \\
0\end{array}$ & $\begin{array}{l}2(40 \%) \\
1(20 \%) \\
2(40 \%)\end{array}$ & $\begin{array}{l}6(50 \%) \\
3(25 \%) \\
3(25 \%)\end{array}$ \\
\hline $\begin{array}{c}\text { Voriconazole } \\
\text { Sensitive } \\
\text { Resistant } \\
\text { Intermediate }\end{array}$ & $\begin{array}{c}25(86.2 \%) \\
3(10.3 \%) \\
1(3.5 \%)\end{array}$ & $\begin{array}{l}3(60 \%) \\
1(20 \%) \\
1(20 \%)\end{array}$ & $\begin{array}{c}2(100 \%) \\
0 \\
0 \\
\end{array}$ & $\begin{array}{l}3(60 \%) \\
1(20 \%) \\
1(20 \%)\end{array}$ & $\begin{array}{l}8(66.6 \%) \\
2(16.7 \%) \\
2(16.7 \%)\end{array}$ \\
\hline $\begin{array}{c}\text { Amphotericin B } \\
\text { Sensitive } \\
\text { Resistant } \\
\text { Intermediate } \\
\end{array}$ & $\begin{array}{c}15(51.7 \%) \\
14(48.3 \%) \\
0\end{array}$ & $\begin{array}{c}2(40 \%) \\
2(40 \%) \\
1(20 \%) \\
\end{array}$ & $\begin{array}{c}1(50 \%) \\
1(50 \%) \\
0\end{array}$ & $\begin{array}{l}2(40 \%) \\
1(20 \%) \\
2(40 \%)\end{array}$ & $\begin{array}{c}5(41.7 \%) \\
4(33.3 \%) \\
3(25 \%) \\
\end{array}$ \\
\hline $\begin{array}{l}\text { Flucytosine } \\
\text { Sensitive } \\
\text { Resistant } \\
\text { Intermediate }\end{array}$ & $\begin{array}{c}22(66.8 \%) \\
5(17.3 \%) \\
2(6.9 \%)\end{array}$ & $\begin{array}{c}4(80 \%) \\
1(20 \%) \\
0\end{array}$ & $\begin{array}{c}2(100 \%) \\
0 \\
0\end{array}$ & $\begin{array}{c}4(80 \%) \\
1(20 \%) \\
0\end{array}$ & $\begin{array}{c}10(83.3 \%) \\
2(16.7 \%) \\
0\end{array}$ \\
\hline
\end{tabular}


Fluconazole and $66.6 \%$ sensitive to Voriconazole. T. inkin showed no resistance toward both Fluconazole and Voriconazole. On the other hand $40 \%$ and $20 \%$ T.mucoides were resistant to Fluconazole and Voriconazole respectively. T.asahii showed $41.4 \%$ resistant to Itraconazole and $25 \%$ of other Trichosporon sp. was resistant to it. (Table 4)

In our study, $48.3 \%$ (15 out of 29) isolates of T.asahii were resistant to AmphotericinB (AMP), whereas $33.3 \%$ (4 out of 12) isolates of other Trichosporon sp. were resistant to it. Among them T.inkin showed 50\% (1 out of 2 isolates) and T.mucoides showed $40 \%$ resistance. On the other hand, T.asahii was $66.8 \%$ sensitive to Flucytosine. In comparison other Trichosporon sp. were $83.3 \%$ (10 out of 12 isolates) resistant to Flucytosine.

Table-5: Antifungal susceptibility of 41 clinical Trichosporon isolates, determined by MIC (mg/lit).

\begin{tabular}{|c|c|c|c|}
\hline Trichosporon sp. & Range of MIC & MIC $_{\mathbf{5 0}}$ & MIC $_{\mathbf{9 0}}$ \\
\hline Fluconazole & $0.25-64$ & 4 & 0.25 \\
\hline Itraconazole & $0.03-2$ & 0.03 & 0.12 \\
\hline Voriconazole & $0.015-0.5$ & 1 & $>16$ \\
\hline Amphotericin B & $0.5>-16$ & 4 & 8 \\
\hline Flucytosine & $0.5-64$ & 0.03 & 8 \\
\hline
\end{tabular}

We also made an attempt to determine $\mathrm{MIC}$ ranges, $\mathrm{MIC}_{50}$ values and $\mathrm{MIC}_{90}$ values for the 41 Trichosporon isolates against 5 antifungal agents as shown in table 5. Most of the isolates exhibited relatively high Amphotericin B MICs. Azoles had good in vitro activity against the Trichosporon isolates, especially Voriconazole which showed $0.12 \mathrm{mg} / \mathrm{lit}$ $\mathrm{MIC}_{90}$. For the isolates with higher Fluconazole MICs, Voriconazole also demonstrated good potency (MIC $\left.\leq 0.5 \mathrm{mg} / \mathrm{lit}\right)$. Susceptibility profiles were similar among the different Trichosporon species and among the different isolates from the various infections.

\section{Discussion}

In the present study, Trichosporon sp. were isolated from 41 patients. Out of 41, 20 had invasive Trichosporonosis whereas 21 patients had probable Trichosporonosis. All of the isolates were identified as Trichospron $s p$. based on $\mathrm{KOH}$ wet mount, colony morphology, gram stain, corn meal test and urease test. Usually Trichosporon sp. is confused with Geotrichium $s p$. as both of them possess arthroconidia.

They are differentiated on the basis of urease test and corn meal test. Trichosporon sp. are urease test positive and both arthroconidia and blastoconidia seen in corn meal test whereas Geotrichium $s p$. is urease test negative and hockey stick shaped arthroconidia seen without blastoconidia [8]. All the suspected were further tested with API ID 32C. By this we were able to do speciation into T.ashaii, T.mucoides and T. inkin. In our study, T.asahii was the most common Trichosporon $s p$ isolated $(70.7 \%, 29$ out of 41). Similar to our study, T.asahii was also the commonest Trichosporon sp. isolated from Japan, Turkey, Taiwan and Brazil [1720]. In one of the largest multicentre retrospective study on invasive Trichosporon infections, they found that $T$. asahii accounted for $61 \%$ (17of 28) of cases [21].
In our study Trichosporon sp. was isolated from wide range of clinical specimen. Blood stream infection was most common (31.7\%) form of trichosporonosis. All of them were proven invasive trichosporonosis (13 out of 20 i.e. $65 \%$ ). 8 out of 20 were reported from NICU. Cases on neonatal sepsis due to T.asahii were also reported from India by Vashishtha et al [22]. Fungemia due to Trichosporon was most common in cancer patients as reported by Girmenia et al $(74.7 \%)$ [21].

Unlike other study in which $T$. asteroides was the second most common cause of blood stream infection, in our study $T$. mucoides was second most common causative species causing blood stream infection [20]. In that study, 7 T. mucoides had been reported to be associated mostly with invasive infection [20].

In our study, urinary tract infection (UTI) was second most common form of trichosporonosis (24.4\%). In India different case report about T.asahii causing UTI had been published at different point of time [23, 24]. Like our study other than blood and urine, Trichosporon $s p$. had been isolated from pus, soft tissue, respiratory specimens and CSF [25,26]. 
Majority of trichosporonosis occur in immunecompromised person, especially in cancer or neutropenic patients [27]. But in our study we came across other risk factors such as extreme of age, indwelling catheter, prior antibiotic uses, prolonged ICU stay, use of steroid and dialysis which was also reported by other author $[27,28]$. Trichosporon $s p$. has the ability to produce biofilm, different enzymes like proteases and phospholipases, morphological switching and cell wall antigenic components like glucuronoxylomannan acts as virulence factors. Also associated bacterial and Candida infection increase the invasiveness of Trichosporon sp. [27].

Antifungal susceptibility pattern: There is no guideline for treatment of invasive trichosporonosis due to lack of well-designed clinical studies as well as emerging nature of the disease. So in vitro susceptibility testing can provide some useful evidence for guiding the treatment. In our study, we observed the emergence of antifungal resistant strain of Trichosporon sp, which is a matter of great concerned in clinical point of view. In the present study, in comparison to AmphotericinB, azoles showed good potency against $T$. asahii isolates, especially Voriconazole.

Among azoles, Itraconazole was least sensitive (51.7\%) whereas Fluconazole was $(72.4 \%)$ sensitive in T.asahii. So, our study suggests that azoles are the preferred antifungal agents for invasive Trichosporonosis and that Voriconazole can be the drug of choice. Study by Chagas et al on 22 Trichosporon isolates also showed poor susceptibility to AmphotericinB but good in vitro susceptibility to azole [20]. In their study, Rodriguez Tudela et al found that MICs of T. asahii isolates for Amphotericin B were $\geq 2 \mu \mathrm{g} / \mathrm{ml}[29]$. In a study done in Taiwan on 101 strains of T. asahii, a low susceptibility to Fluconazole and Amphotericin B was observed and Voriconazole was suggested as drug of choice [19]. Emergence of resistant strain of Trichosporon sp. had been reported from different part of world including Turkey, Italy etc $[18,21]$, but not from India.

The mechanism of antifungal resistant is not known in Trichosporon sp. Molecular study can give some light on it. But due to financial constrain we were unable to do it. Increased and indiscriminate use of antifungal drug may lead to selection and isolation of more resistant strain in the future. As this is a tertiary health care center, most of the patients were referred from other hospital and nursing home and were already on different antibiotics and antifungal agents. That may be the reason of emergence of resistant strain.

\section{Conclusion}

This present study indicates strongly that T.asahii and other Trichosporon sp. have the propensity to cause life threatening invasive Trichosporonosis. The emergence of drug resistance in Trichosporon sp. must be kept in mind during treatment. So, we recommend to do the species identification of Trichosporon $s p$. for all clinically relevant isolates as well as to determine susceptibility testing of antifungal drugs for better patient care. To the best of our knowledge, this is the first and largest study on Trichosporon $s p$. not only in tribal dominated state of Chhattisgarh but also in this central region of India.

\section{Funding: Nil, Conflict of interest: None Permission of IRB: Yes}

\section{References}

1. Chander J. Text book of Medical Mycology. $3^{\text {rd }}$ Ed. Mehta publishers; 2009. Chapter 1, Introduction; p.2-18.

2. Pffaler M, Diekema D. Epidemiology of Invasive Candidiasis: A Persistent Public Health Problem. Clin Microbiol Rev. 2007; 20(1) :133-63.

3. Pradhan S, Singh S, Samal M.P., Murthy R, Pandey S. Characterization and Antifungal Susceptibility Pattern of Candida spp. Isolated from Clinical Specimens. J of Evolution of Med and Dent Sci.2015; 4, Issue 40: 7004-7012. DOI:10.14260 /jemds/ 2015/ 1017.

4. Chowdhary A, Ahmad S, Khan Z U, Doval D C, Randhwa H S. Trichosporon asahii as an emerging etiologic agent of disseminated Trichosporonosis: A case report and an update. Ind J Med Microbiol,2004: 22:16-22.

5. William G. Merz and Roderick J. Hay. Topley \& Wilsons Microbiology and Microbial Infections : Medical Microbiology. 10 ${ }^{\text {th }}$ edition; Wiley Publication; 2005. Chapter 31, Serious Infections caused by uncommon yeasts : 624-635.

6. Middlehoven WJ. Identification of clinically relevant Trichosporon species. Mycoses.2003; 46:7-11. 
7. Fisher F, Cook N. Fundamentals of Diagnostic Mycology, Saunders, 1998: 196-230

8. Chander J. Text book of Medical Mycology, $3^{\text {rd }}$ Ed. Mehta publishers; 2009. Chapter 26, Miscellaneous Oppotunistic Mycoses;p 387-398.

9. Chagas-Neto TC, Chaves GM, Colombo AL. Update on the genus Trichosporon. Mycopathologia. 2008 Sep; 166(3):121-32. doi: 10.1007/s11046-008-9136-x. Epub 2008 Jun 21.

10. Ahmad S, AL - Mahmeed M, Khan ZU. Characterization of Trichosporon Species isolated from clinical specimens in Kuwait. J. Med Microbiol . 2005; 54: 639-46.

11. Pini G, Faggi E, Donato R, Fanci R. Isolation of Trichosporon in a hematology ward. Mycoses. 2005; 48:45-9.

12. Krcmery V Jr, Mateicka F, Kunova A et al,Haematogenous Trichosporonosis in cancer patient: Report of 12 cases including 5 during prophylaxis with Itraconazole. Support care cancer 1999; 7: 39-43.

13. De Pauw B, Walsh TJ, Donnelly JP, et al. Revised Definitions of Invasive Fungal Disease from the European Organization for Research and Treatment of Cancer/Invasive Fungal Infections Cooperative Group and the National Institute of Allergy and Infectious Diseases Mycoses Study Group (EORTC/MSG) Consensus Group. Clinical infectious diseases: an official publication of the Infectious Diseases Society of America. 2008; 46(12): 1813-1821. doi:10.1086/ 588660 .

14. Rex JH, Pfaller MA, Walsh TJ, Chaturvedi V, Espinel-Ingroff A, Ghannoum MA, Gosey LL, Odds FC, Rinaldi MG, Sheehan DJ, Warnock DW. Antifungal susceptibility testing: practical aspects and current challenges. Clin Microbiol Rev. 2001 Oct;14(4): 643-58, table of contents.

15. Pfaller MA, Diekema DJ, Rex JH, et al. Correlation of MIC with Outcome forCandida Species Tested against Voriconazole: Analysis and Proposal for Interpretive Breakpoints. Journal of Clinical Microbiology. 2006;44(3):819-826. doi:10.1128/JCM. 44.3.819-826.2006.
16. CLSI (2008a) Reference Method for Broth dilution Antifungal Susceptibility Testing of yeasts; approved standard- third edition; CLSI document M27-A3. Clinical and Laboratory Standards Institute, Wayne

17. Sugita T, Nakajima M, Ikeda R, Matsushima T, Shinoda T. Sequence analysis of the ribosomal DNA intergenic spacer 1 regions of Trichosporon species. J Clin Microbiol. 2002 May;40(5):1826-30.

18. Kalkanci A., Sugita T, Arikan S, Yucesoy M, Ener B, Otag F, Kiraz N. et al. Molecular identification, genotyping, and drug susceptibility of the basidiomycetous yeast pathogen Trichosporon isolated from Turkish patients. Med Mycol. 2010 Feb; 48 (1): 141-6. doi: 10.3109/13693780902977984.

19. Sugita T, Nakajima M, Ikeda R, Matsushima T, Shinoda T. Sequence analysis of the ribosomal DNA intergenic spacer 1 regions of Trichosporon species. J Clin Microbiol. 2002 May;40(5):1826-30.

20. Chagas-Neto T.C., Chaves G.M., Melo A.S., Colombo A.L. Bloodstream infections due to Trichosporon spp.: species distribution, Trichosporon asahii genotypes determined on the basis of ribosomal DNA intergenic spacer 1 sequencing, and antifungal susceptibility testing. J ClinMicrobiol. 2009 Apr; 47(4): 1074-1081.

21. Girmenia, C., L. Pagano, B. Martino, D. D’Antonio, R. Fanci, G. Specchia, L. Melillo, M. Buelli, G. Pizzarelli, M. Venditti, and P. Martino. Invasive infections caused by Trichosporon species and Geotrichum capitatum in patients with hematological malignancies: a retrospective multicenter study from Italy and review of the literature. J. Clin. Microbiol. 2005 Apr; 43(4): 1818-1828.doi: 10.1128/JCM. 43.4. 1818-1828.2005

22. Vashishtha VM, Mittal A, Garg A. A fatal outbreak of Trichosporon asahii sepsis in a neonatal intensive care Unit. Indian Pediatr. 2012 Sep;49(9):745-7.

23. Khan ID, Sahni AK, Basu A, Haleem S. Trichosporon asahii urinary tract infection in immunocompetent patients. Med J Armed Forces India. 2015 Oct;71(4):373-6.doi:10.1016/j.mjafi.2014.08. 013. Epub 2014 Nov 6. 
24. Sood S, Pathak D, Sharma R, Rishi S. Urinary tract infection by Trichosporon asahii. Indian $\mathrm{J}$ Med Microbiol. 2006 Oct;24(4):294-6.

25. Wolf DG, Falk R, Hacham M, Theelen B, Boekhout T, Scorzetti G, Shapiro M, Block C, Salkin IF, Polacheck I. Multidrug-resistant Trichosporon asahii infection of nongranulocytopenic patients in three intensive care units. J Clin Microbiol. 2001 Dec;39(12): 4420-5.

26. Saad J. Taj-Aldeen, Naseer Al-Ansari, Sittana El Shafei, Jacques F. Meis, Ilse Curfs-Breuker et al. Molecular Identification and Susceptibility of Trichosporon Species Isolated from Clinical Specimens in Qatar: Isolation of Trichosporon dohaense TajAldeen, Meis \& Boekhout ap.nov J Clin. Microbiol. 2009;47(6):1761-1799.
27. Walsh TJ, Melcher GP, Lee JW, Pizzo PA. Infections due to Trichosporon species: new concepts in mycology, pathogenesis, diagnosis and treatment. Curr Top Med Mycol 1993; 5:79-113.

28. Colombo AL, Padovan AC, Chaves GM. Current knowledge of Trichosporon spp. and Trichosporonosis. Clin Microbiol Rev. 2011 Oct;24(4):682-700. doi: 10.1128/CMR.00003-11.

29. Rodriguez-Tudela JL, Diaz-Guerra TM, Mellado E, Cano V, Tapia C, Perkins A, Gomez-Lopez A, Rodero L, Cuenca-Estrella M. Susceptibility patterns and molecular identification of Trichosporon species. Antimicrob Agents Chemother. 2005 Oct; 49(10): 4026-34.

\section{How to cite this article?}

Pradhan S, Agrawal E, Murthy R, Tomar R. Prevalence of invasive Trichosporonosis by Trichosporon asahii and other Trichosporon species and their antifungal susceptibility pattern in Chhattisgarh. Int J Med Res Rev 2017;5(03):285-292 doi:10.17511/ijmrr. 2017.i03.12. 